\title{
El Padre Carlos Felipe Beltrán: planteamientos de una educación indígena y bilingüe en Bolivia (1862-1892)
}

\author{
Weimar Giovanni Iño Daza ${ }^{1}$ \\ ${ }^{1}$ Universidad Mayor de San Andrés. Facultad de Humanidades y Ciencias de la Educación. Instituto de Estudios \\ Bolivianos. Avenida 6 de agosto n. ${ }^{\circ}$ 2080, 2do. Piso de la Casa Montes, Barrio de Sopocachi. La Paz. \\ Bolivia.willkaweimar13@hotmail.com.
}

RESUMEN. El artículo es una aproximación histórica a la educación indígena en Bolivia, con el propósito de visibilizar la experiencia y aporte del padre Carlos Felipe Beltrán. El método histórico y la técnica del fichaje permitieron recopilar, describir y analizar las fuentes escritas. El artículo, por un lado, busca ofrecer un panorama de las políticas educativas aplicadas en Bolivia durante los últimos 40 años del siglo XIX (1862-1892), los cuales fueron implementados aisladamente. Por otro lado, el dilucidar la experiencia del educador bilingüe el padre Beltrán con respecto a la educación indígena, que planteó una alfabetización y catequización bilingüe en los idiomas aymara y quechua, a partir de la revalorización cultural, de su historia y de su lengua. En suma Beltrán fue precursor del indigenismo y desplegó las bases de una educación bilingüe, intercultural y productiva.

Palabras clave: Educación Boliviana Siglo XIX, Educador Carlos Felipe Beltrán, Educación Indígena, Educación Bilingüe, Aymaras, Quechuas. 


\title{
The Priest Carlos Felipe Beltrán: Approaches of indigenous and bilingual education in Bolivia (1862-1892)
}

\begin{abstract}
The article is a historical approach to indigenous education in Bolivia, with the purpose of making the experience and contribution of Father Carlos Felipe Beltrán visible. The historical method and the technique of the signing allowed to compile, to describe and to analyze the written sources. The article, on the one hand, seeks to provide an overview of the educational policies applied in Bolivia during the last 40 years of the nineteenth century (1862-1892), which were implemented in isolation. On the other hand, to elucidate the experience of the bilingual educator Father Beltrán with respect to indigenous education, which raised bilingual literacy and bilingual catechization in the Aymara and Quechua languages, based on cultural revaluation, history and language. In short, Beltrán was a precursor of indigenism and laid the foundations for a bilingual, intercultural and productive education.
\end{abstract}

Keywords: Bolivian Education in the Nineteenth Century, Educator Carlos Felipe Beltrán, Indigenous Education, Bilingual Education, Aymaras, Quechua. 


\section{Padre Felipe Carlos Beltrán: abordagens dos indígenas e educação bilíngue na Bolívia (1862-1892)}

RESUMO. O artigo é uma aproximação histórica da educação indígena na Bolívia, a fim de visualizar a experiência e contribuição de Padre Carlos Felipe Beltran. O método e a técnica de pesquisa histórica utilizadas neste estudo permitiram coletar, descrever e analisar as fontes escritas e analisadas. O artigo, por um lado, tem o objetivo de proporcionar uma visão geral das políticas educacionais na Bolívia nos últimos 40 anos do século XIX (1862-1892), que foram implementadas de forma isolada. Por outro lado, elucida a experiência do educador bilíngue Padre Beltrán sobre a educação indígena, que proporcionou a alfabetização e doutrinação bilíngue nas línguas Aymara e Quechua, de apreciação cultural, histórica e de sua linguagem. Em suma, Beltrán foi um precursor do indigenismo, ao implantar a base de uma educação intercultural bilíngue e produtiva.

Palavras-chave: Educação Boliviana do Século XIX, Educador Carlos Felipe Beltrán, Educação Indígena, Educação Bilíngue, Aymaras, Quéchuas. 


\section{Introducción}

El artículo es un estudio histórico ${ }^{\mathrm{i}}$ que recurre al método histórico, ${ }^{\text {ii }}$ así como el sub-método, el cronológico. ${ }^{i i i}$ En la revisión bibliográfica se utilizó la técnica del fichaje para la consulta de fuentes escritas oficiales, primarias y secundarias. ${ }^{\text {iv }}$ Esto con el propósito de ofrecer una mirada histórica a las políticas educativas aplicadas en Bolivia entre 1862-1892, así como la experiencia educativa del padre Carlos Felipe Beltrán.

En Bolivia desde 1863 varias políticas agrarias arremetieron contra la propiedad comunitaria de la tierra. En décadas posteriores están las disputas internas por el poder político, el surgimiento de los partidos políticos, la apertura comercial a las importaciones y la Guerra del Pacífico (1879).

En lo educativo, durante los últimos 40 años del siglo XIX los gobiernos buscaron la descentralización de la instrucción pública: el nivel primario pasó a manos de los municipios y el secundario a la iniciativa privada y a la enseñanza libre. Se declaró la obligatoriedad de la instrucción primaria en 1874 ratificada en la Constitución Política del Estado de 1880. Para la implementación de la instrucción indígena el Estado acudió a la iglesia católica.
En ese contexto, el padre Carlos Felipe Beltrán, educador bilingüe y precursor del indigenismo, desde su labor religiosa pone en marcha una experiencia pedagógica orientada a ofrecer una educación indígena y bilingüe. $\mathrm{Su}$ propósito fue ampliar la instrucción hacia la mayoría indígena y "arrancar de la ignorancia por medio de la educación". En un escenario histórico donde para los grupos dominantes los indígenas representaban paradójicamente, por un lado, el peligro y atraso del desarrollo de la nación, pero por otro lado, el sostén económico.

\section{Políticas educativas en el siglo XIX en Bolivia (1862-1892): iniciativas aisladas}

En el contexto de los gobiernos conservadores existe una relación entre el tema de la propiedad de la tierra y educación. Con referencia a las políticas agrarias entre 1863-1902 buscaron disolver legalmente las comunidades originarias con la titulación individual de la propiedad colectiva, en donde las comunidades dejaban de ser sujetos fiscales, generando en los indígenas su conversión en colonos de las haciendas.

Este ciclo comienza con el Decreto de 28 de febrero de 1863, con la intención de convertir a los forasteros en 
contribuyentes al igual que los originarios. La desestructuración de la propiedad comunal buscaba declarar al Estado como propietario de las tierras de las comunidades (DS 20 de mayo de 1866 y Ley de 28 de septiembre de 1868). La Ley de Ex-vinculación (5 de octubre de 1874) genera la extinción definitiva de los ayllus, la privatización de la tenencia y la creación de un mercado de tierras que permitiera la formación de grandes propiedades agrícolas. (Platt, 1982, p. 15).

En el caso de la educación se promulgaron una serie de estatutos y normas. Para Suárez (1963) fueron aisladamente sin un plan orgánico general. Por ejemplo, en el gobierno del General José María Achá (1861-1864), la política educativa planteó introducir la cultura occidental, la apertura de escuelas de parte de los municipios, la asistencia obligatoria de los indígenas a las escuelas bajo sanción, la creación de una escuela normal, y se instó a los párrocos a crear escuelas en los pueblos. Pero el panorama era desolador, en la Memoria de Instrucción Pública (1864) Diego Monroy manifestaba que las provincias y cantones carecían de escuelas y la improvisación de maestros analfabetos (citado por Iño, 2009, p. 118).

La revolución de 1870 depuso a Mariano Melgarejo, el gobierno de Agustín Morales (1871-1872), trató de reorganizar la educación. Labor designada al Ministro de Instrucción Melchor Terrazas, quien debía procurar la centralización de las universidades, el mejoramiento de métodos de enseñanza, fundar una escuela normal (30 de abril de 1872) y la creación de escuelas nocturnas y dominicales para adultos (Decreto 29 de abril de 1872).

Así como la descentralización de la educación pública: la instrucción primaria pasó a manos de los municipios, la media (secundaria) y superior a la iniciativa privada. La Ley de Libre Enseñanza del 22 de noviembre de 1872 "buscaba educar a los hijos de la gente pobre" para la industria y el trabajo (Rodríguez, 1995, p. 43-45), la cual no llegó a concretarse en el caso de los indígenas.

En plena Revolución de 1870, aparece la propuesta de Casimiro Corral $L a$ doctrina del pueblo (1871), en la que identifica la necesidad de constituir una verdadera república democrática, para ello era necesaria la instrucción del pueblo, el trabajo como base del progreso y la homogeneidad cultural y lingüística. Para Lora (1979 citado por Choque \& Quisbert, 2006, p. 52) propuso la instrucción indígena para convertirlo en ciudadano con los mismos derechos que los demás, pero desterrando sus valores apocados por la civilización de sus explotadores. 
De acuerdo a Irurozqui (2001, p. 414), el planteamiento Corral sobre la instrucción residían, primero, en convertir a los bolivianos en "pueblo" y no en "populacho"; segundo, en eliminar el desorden nacido de la tiranía y la anarquía; $\mathrm{y}$, tercero, en acrecentar el patriotismo. Esa necesidad explica por qué Corral concebía la educación como un derecho y una obligación, cuya prioridad era inculcar el buen juicio y las costumbres republicanas.

Corral buscaba la homogeneización y la asimilación cultural al mundo occidental de la mayoría indígena: "Metamorfoseando al indio con nuestro traje, ya no se avergonzaría de su condición, cesarían su abatimiento y abyección, aspiraría a ser algo más de lo que es actualmente y tendría que trabajar más para satisfacer las nuevas necesidades que vienen siempre en pos de la ilustración". (Corral, 1871, p. 91).

También planteó su castellanización e igualdad jurídica:

Si el indio hablase nuestro idioma sería franco, sincero y desembarazado con nosotros; porque el continuo trato y comunicación con los que hablan el idioma nacional sería un constante aprendizaje para él: así se instruiría fácilmente. Entonces el indio dejaría la estrechez de su modo de vivir, abandonaría su natural estupidez y apocamiento y aspiraría a otra vida, a otros goces, a otras comodidades; y entonces conocería sus derechos y obligaciones correlativas y ya no sería la mercadería de explotación del párroco, de las autoridades y del patrón; entonces, comprendiendo que tiene los mismos intereses, derechos y garantías y porvenir que nosotros, trabajaría con agrado para elevarse como hacen los demás (Ibíd., p. 92).

$\mathrm{Su}$ incorporación a la sociedad boliviana sería por medio de su civilización:

Es tiempo de divorciar al indio con sus tradiciones, su fanatismo, su abyección e ignorancia, rompiendo los diques que lo tienen alejado de nosotros y que detienen su progreso y civilización. Es tiempo de sacarlo de su triste condición, instruyéndole y enseñándole a conocer las ventajas de la libertad. Sólo así el indio se aproximará a nosotros, cesará su odio y no vivirá constantemente prevenido contra los que no son de su raza (Ibíd., p. 92).

Para Corral (1871) la diversidad de "razas y lenguas", por un lado, era un obstáculo del progreso nacional, y por otro lado, una amenaza contra los blancomestizos. De este modo, la instrucción indígena debía ser responsabilidad del Estado, un derecho que debía extenderse hacia la mayoría indígena para su conversión en "ciudadanos útiles, inteligentes, industriosos y amantes de su patria" y de una "república democrática". (Irurozqui, 2001, p. 416).

Al igual que Corral, Alcocer en 1872 manifestaba que la educación es uno “de 
los elementos más poderosos de progreso social", su instrucción conduciría a la formación de un ciudadano: "formar y educar una generación de niños era formar un pueblo". (Alcocer, 1872, p. 3-8). Así, para Corral y Alcocer la educación es la base fundamental para la formación de un "pueblo soberano" con ciudadanos patrióticos, civilizados y democráticos.

Pese a estas propuestas y sugerencias la aplicación de políticas a favor de la instrucción indígena no llegó a concretarse. Como lo sugiere Irurozqui (1999), en la práctica no llegaba a la población nativa, debido al alcance urbano de las jurisdicciones municipales y a la carencia de recursos económicos. "Los gobiernos anteriores a los liberales de principios de siglo XX no tenían una posición política e ideológica definida, ni se interesaron seriamente por la educación de las masas indígenas sumidas en la ignorancia de sus derechos". (Choque \& Quisbert, 2006, p. $51)$.

En la presidencia de Adolfo Ballivián (1873-1874), el Decreto de 15 de enero de 1874 puso en vigencia el Estatuto General de Instrucción Pública, que dividió la educación en tres ciclos: popular, media y profesional; ratificó la instrucción primaria como gratuita y obligatoria; la enseñanza libre en todos los grados; la creación de una escuela normal de instructores. En cuanto a la instrucción popular solicitó a la iglesia católica la creación de escuelas. "Por una circular especial incitó a los Obispos para que pudieren fundar escuelas en sus parroquias". (Suárez, 1963, p. 150).

En los gobiernos de Tomás Frías (1874-1876) y Narciso Campero (18801884) siguió aplicándose el Estatuto de 1874. Por los sucesos de la Guerra del Pacífico (1879) la instrucción no sufrió modificaciones. El 12 de diciembre de 1880 se crea el Consejo Supremo de Instrucción, posteriormente suprimido en la presidencia de Gregorio Pacheco (18841888).

Según Irurozqui (1999), a fin de generalizar la instrucción primaria $\mathrm{y}$ difundirla a todas las capas de la sociedad, la Constitución de 1880 declaró a la instrucción primaria gratuita y obligatoria, siendo su atención responsabilidad de las municipalidades. "El ministro de Instrucción Pedro Vargas en su informe al Congreso de 1882, manifestaba que la educación implicaba realizar una campaña interna para combatir el analfabetismo". (Torrico, 1947, p. 114). Por lo tanto, el Estado debía retomar su responsabilidad de la instrucción popular.

En 1888, se trató de reorganizar la instrucción pública con criterio científico, uno de los temas tratados fue la formación 
docente. Según Iño (2009, p. 119), para solucionar el problema, en cada capital de departamento debían reunirse los maestros para recibir lecciones de Pedagogía y Metodología de la Enseñanza.

El gobierno de Mariano Baptista (1892-1896) buscó la racionalización y uniformidad de la instrucción pública, particular, parroquial y municipal con la Ley del Sistema Gradual Concéntrico del 12-X-1892, en el sistema gradual la enseñanza debía transitar de lo simple a lo complejo, y de lo fácil a lo difícil. También se organizaron escuelas de artes y oficios, taquigrafía, telegrafía, agricultura, las sociedades protectoras de instrucción, y la fundación de la "Escuela Normal" en Tarija que resultó infructuosa por la falta de personal e inestabilidad. (Iño, 2009, p. 119).

La Ley de 15 de octubre de 1892 dispuso la creación de universidades en los departamentos de Oruro y Potosí. En 1896, Felipe Guzmán trató de sentar las "bases para la instrucción agrícola". (Torrico, 1947, p. 121).

$\mathrm{Al}$ igual que en los 60 y 70 la instrucción indígena al finalizar el XIX, quedó desatendida por parte del gobierno central.

Los gobiernos, hasta hoy solo han prestado una débil protección a la instrucción popular; de aquí resulta que el número de ciudadanos capaces de poder ejercer los derechos que le da la ciudadanía. Difundiese la instrucción hágase que ella llegue hasta la miserable cabaña y entonces recién podremos decir que nuestras masas conocerán lo que el nombre de Patria significa (El Porvenir, 8 de abril de 1885, p. 2).

La iniciativa recayó en los párrocos y de las municipalidades la creación de nuevas y el mantenimiento de las vigentes. Por ejemplo, en el departamento de Oruro, la población y sociedad reclamaba instrucción para los indígenas. Los llamados a realizar esta labor social, eran los clérigos y religiosos para fundar escuelas parroquiales. "Los párrocos, que a quienes debía estar ella librada en los cantones y aldeas, la descuidan por completo, salvo algunos que cumplen con este precepto verdaderamente evangélico 'enseñar al que no sabe"”. (El Porvenir, 8 de abril de 1885 , p. 2).

El indio, el mestizo, o el salvaje, no encuentran la mano protectora que pudiera prodigarles los beneficios de la religión y las luces de la instrucción: viven sumergidos en la ignorancia y la depravación de costumbres. Para esos desagraciados, esa porción sumida en la abyección y la miseria demandan hoy, como siempre, la protectora acción del parroquiado (La Violeta, 9 de mayo de 1895, p. 1).

De este modo, la educación indígena en el imaginario social constituía en una 
imperiosa necesidad para sacar a Bolivia del atraso: "es necesario educar e instruir al pueblo; esto lo repetiremos sin cansarnos, porque es lo único a que han de tender nuestros esfuerzos en el constante afán que tenemos de hacer fructíferas nuestras labores". (La Ley, 19 de marzo de 1897, p. 2).

Las políticas agrarias avanzaron a la conversión de los indígenas comunarios en colonos, mientras las políticas educativas a favor de la instrucción indígena fueron realizadas por los párrocos y los municipios. De acuerdo a Mamani (1991, p. 129), la educación del indígena fue con el fin de civilizarlo e incorporarlo a la cultura occidental a través de la alfabetización.

Según Irurozqui (1999), la instrucción del indio conllevaba el riesgo de transformarlo en ciudadano, de hacer de él un boliviano con voto y decisión, estado que no era aceptado por los sectores dominantes. Por ello, su integración a la nación a finales del siglo XIX fue su conversión en colono de hacienda; y no así desde su educación que debía transformarlo en ciudadano.

Para Ticona (2004, p. 1) por la política estatal, alrededor de 1880 se constituye un movimiento indígena, denominado los Apoderados Generales. Por un lado, defendieron las tierras comunitarias con la presentación de Títulos de Composición otorgados por la corona española en la colonia. Por otro lado, buscaron el acceso a la educación a través de solicitudes de fundación de escuelas elementales.

De acuerdo a Irurozqui (1999) las peticiones de ciudadanía expresadas por la población indígena a lo largo de los siglos XIX y XX están vinculadas con el tema de la educación y de la propiedad de la tierra. La educación fue entendida como un bien que dotaba a la persona del status social necesario, la ciudadanía, para exigir al Estado la defensa de intereses tanto individuales como corporativos.

\section{El padre Carlos Felipe Beltrán: educador bilingüe y "amigo de los indios"}

Carlos Felipe Beltrán nació en la localidad de Chayanta, en el pueblo de Uqurí del Departamento de Potosí, el 23 de agosto de 1816 y fallece en la ciudad de Oruro el 31 de enero de 1898. En 1827, a la edad de once años realiza sus estudios en el Colegio Nacional Bolívar de la ciudad de Oruro. Según Massud (2006), no existe fecha exacta del ingreso al Seminario Conciliar de San Cristóbal de la ciudad de Sucre. Parece que Beltrán cursó un doctorado en Teología y la carrera de 
Derecho en Sucre. De acuerdo a Barnadas (2002), obtuvo el bachillerato en Derecho.

En 1845 fue ordenado sacerdote, recibe de manos del Prelado Mendizábal las Tres Órdenes Mayores: el Subdiaconado, la del Diaconado y la del Presbiterado, lo que posibilitó su habilitación para ingresar en el ministerio parroquial. (Massud, 2006, p. 27). Beltrán como sacerdote prestó servicios en Potosí (1845 a 1861), en Nor Lípez específicamente en Llica-Tahua (1854), Sakaka (1879) y (1885). En Oruro, en Quillacas (1862) y (1871), Toledo (1871), (1872) y (1876), Quntu Quntu (1876) y (1879), y nuevamente en Toledo (1886 hasta 1896). Para Massud (2006) esta última etapa transcurre más en la ciudad de Oruro que en Toledo.

Según Beltrán (1948), fue filólogo, escritor americanista, orador, legislador y pedagogo. Su verdadero aporte reside en la obra publicista a favor de la "alfabetización, lectura, catequesis, y civilización de la población de habla quechua y aymara del país”. (Barnadas, 2002, p. 282). "Su obra es diversa, pero siempre con un leiv motiv: la civilización del indio". (Beltrán, 1948, p. 51). Para Barnadas (2002), abarca tres ámbitos principales: la catequesis y devoción católica; la didáctica de la escritura en lenguas andinas; la recopilación y desarrollo del patrimonio literario andino (cantos, poesías, cuentos, leyendas, teatro).

De acuerdo a Barnadas (2002) fue elegido parlamentario, asistió a la Constituyente de 1877-1878 y al Congreso de 1889. "Intervino en la décima Constitución, teniendo entonces $\mathrm{y}$, posteriormente, oportunidad de defender ardorosa, fogosamente sus puntos de vista en pro de la educación y las comunidades indígenas”. (Beltrán, 1948, p. 52).

A decir de Massud (2006), los trabajos de recopilación de leyendas, tradiciones, mitos, cantos, cuentos y otros convierten al padre en un etnógrafo, puesto que la información que recogió la hizo mientras vivió entre los indios. "Este investigador minucioso y severo de nuestras tradiciones fue, efectivamente, cura en los alejados pueblos de Quillacas, Llica, Sacaca, etc., donde prefirió vivir por recoger en sus propias fuentes el oro puro del folklore racial”. (Beltrán, 1948, p. 52).

$\mathrm{Su}$ vivencia en las distintas comunidades le posibilitó poner en marcha su labor pedagógica: educación moral, bilingüe y propia. "Todo ello fruto de su diagnóstico de la realidad". (Barnadas, 2002, p. 282). Beltrán fue un educador bilingüe y un precursor del pensamiento indígena, como lo menciona Barnadas (1998), fue un "amigo de los indios." 


\section{El indigenismo del padre Beltrán: una reivindicación cultural de lo indígena}

En Beltrán existe la presencia del indigenismo expresado en una fuerte reivindicación cultural de lo indígena. Como lo sugiere Medinaceli (1944), su obra es de un verdadero apóstol de la educación del indio. "Debe considerársele como el más conspicuo precursor del 'movimiento indianista' de hoy." Para Rivet y Rodríguez (1951), es el salvador del folklore indígena para goce y cultura de las presentes y futuras generaciones.

Según Massud (2006), hay una añoranza por el pasado de los quechuas y de los aymaras. En varias de sus publicaciones acude a la reminiscencia e idealización del pasado incaico.

Un gobierno paternal, lleno de bondad, donde el inca, más patriarca que rey, trataba con dulzura a sus súbditos: régimen en el que estos, movidos por un sentimiento de gratitud, aceptaban la sumisión obedeciendo voluntariamente a una tutela tan benévola; paz perpetua, conquistas pacíficas, tal es la utopía incásica de Beltrán (Rivet \& Rodríguez, 1951, p. 84).

Como indigenista criticó seriamente a la conquista y a la configuración del régimen colonial, como el escenario que generó los vicios sociales, es decir, planteó las primeras aproximaciones sobre el "colonialismo interno": “...los indios sólo han sido considerados como meros instrumentos de producción y lejos de dar un paso hacia su elevación y grandeza, ha retrocedido...Más abyección y más vicios, he ahí los legados de la conquista". (Beltrán, 1870, p. 10).

Beltrán, ponía en evidencia la "condición colonial" del indígena en el período republicano como tributario, minero, agricultor, sirviente, pongo, sostén económico, ignorante, en suma seguía sirviendo como en la colonia: "...nacido para servir, ser empleado en las más viles ocupaciones, sin paga o por un céntimo, clasificado en la casta de paria, e incapaz de elevarse a nuestra esfera. Por consiguiente se abusa de su impotencia, de su humildad, de su postración”. (Beltrán, 1870, p. 11-12). Como lo sugiere Massud (2006, p. 28) percibe como pocos, la miserable condición de los indios, en una época llena de convulsiones sociales y políticas, en la que los derechos políticos están ausentes para los indígenas.

Beltrán fue comprendiendo la realidad por la que atravesaban los indígenas y fue a partir de su trabajo en las comunidades llegaría a postular la necesidad de su "civilización" por medio de la educación, con una formación religiosa, propia y bilingüe. Elaboró sus cartillas y silabarios sobre la base de la realidad que vivían los indígenas: “...para 
tu instrucción he podido escribir en las soledades, donde hemos vivido juntos, yo presenciando tus dolores, tus sufrimientos y tu lamentable ignorancia, y tú, derramando lágrimas al verte olvidado, postergado, menospreciado...”. (Beltrán, 1872, p. I).

De acuerdo a Barnadas (1998, p. 10), Beltrán debería pasar a la historia como un indigenista pionero. $\mathrm{Y}$ lo fue a su manera: sin intereses subalternos, ni materiales, ni políticos. Fue buscando, por supuesto, el bien de sus destinatarios, porque creía que este era la imperiosa necesidad del conjunto del país. Para Rivet y Rodríguez (1951), fue "más indio que español," surgió al mundo público como el portavoz de una sociedad que él pensaba regenerar. Como lo menciona Beltrán (1948) su gran ideal de vida fue la "civilización del indio", por medio de su instrucción. Por lo que, Beltrán es un defensor de los indígenas, de su cultura, historia y lenguas.

\section{Una educación de los indígenas desde la revalorización cultural}

Los planteamientos pedagógicos de Beltrán son la aplicación de una educación indígena y bilingüe orientada a la civilización y ciudadanización como mecanismos de integración a la nación. De acuerdo a Beltrán (1948), tenía una preocupación por civilizar al indio boliviano.

La educación indígena para Beltrán debía ser desde su historia, su cultura y su idioma, lo que se traduce en principios de una educación propia e intracultural. Según Barnadas (1998), aborda los temas de cultura e idioma porque tiene un amor, una adhesión, un compromiso personal por el patrimonio de la cultura andina. Por lo que existe en su experiencia una fuerte interrelación entre educación y cultura.

Beltrán puso en marcha una educación indígena y propia con un carácter reivindicativo histórico, cultural y lingüístico. "Si queremos civilizar al indio, empecemos por iluminarlo en su propio idioma poniendo en sus manos obras elementales escritas en quechua o aymara, con un alfabeto propio...". (Beltrán, 1888, p. 3). Sus objetivos perseguían la necesidad de educar con el idioma propio, para promover su "ilustración" $\mathrm{y}$ “civilización". La acción reivindicativa y civilizadora estaban orientadas en:

$1^{\circ}$. Hacer tan susceptibles de lectura $\mathrm{y}$ escritura los idiomas quechua $\mathrm{y}$ aymara como el mismo español.

$2^{\circ}$. Poner en manos de los indios obras elementales de religión, ciencias y artes, escritas en su propio idioma y en el español para que con el auxilio de aquel, entiendan este, y con la inteligencia del español fecundicen sus ideas y se estimulen a su adelantamiento. 
$3^{\circ}$. Infiltrar en estos infelices el amor al estudio y a la adquisición de conocimientos, haciéndoles gastar sus delicias en su propio idioma.

$4^{\circ}$. Arrancarlos suave y paulatinamente de su barbarie y de sus vicios con el conocimiento de las cosas divinas y humanas en su lengua y la nuestra.

$5^{\circ}$. Civilizarlos, desbastarlos, pulirlos, instruirlos y hacerlos gratos a nuestro corazón y a nuestro trato por sus maneras, su limpieza, su urbanidad, y el caudal de sus ideas y amables dotes (Beltrán, 1870, p. 14).

La civilización debía buscar la igualdad social y política de los indígenas ante el Estado, leyes y sociedad republicana. Por ello la instrucción debía ser sobre la base de sus virtudes $y$ cualidades, en su propio idioma y alfabeto:

...solo entonces, su entendimiento, desembrollado del caos que hoy lo envuelve, empezará a comprender las bellezas del mundo intelectual, se aficionará al estudio, y con ávidas ansias devorará un libro escrito en su idioma; y si estos libros elementales llevan su versión castellana como deben llevar, y se le ofrecen otros gradualmente más luminosos, entonces, esa estatua hoy inanimada se llenará de vida y se presentará ante el mundo civilizado que hoy la desprecia (Beltrán, 1888, p. 3-4).

Como lo menciona Massud (2006), solo a través del conocimiento de estas lenguas pudo el padre redescubrir y revalorar el patrimonio cultural de los indígenas. Puesto que por medio de la lengua y la tradición oral, las generaciones viejas trasmiten su cultura, historia, mitos y tradiciones a las generaciones nuevas, es decir, Beltrán comprende y reconoce la importancia de la enculturación en las culturas aymara y quechua.

Beltrán despliega en su experiencia educativa, las nociones de la etnoeducación, modelo educativo que parte de los propios principios culturales que permiten fortalecer la identidad cultural. Según Podesta (1987, p. 68), la etnoeducación debe partir de los contenidos culturales propios para generar un rico proceso de socialización que apunte a aumentar la identidad con lo propio y a diferenciar claramente lo externo culturalmente.

\section{Educación bilingüe: alfabetización y catequización en quechua y aymara}

Beltrán desarrolla una educación bilingüe que retoma la cultura, historia e idioma de los quechuas y aymaras. Asimismo, tiene una doble acción pedagógica: por un lado, la alfabetización y por otro lado, la cristianización (lo moral). Como lo menciona Beltrán (1892, p. 2), con la educación se ilumina al indio, con el amor a Dios se logra fe, anhelo y devoción, es decir, una educación moral. Según Iño (2010, p. 290), la civilización e instrucción planteada debía ser mediante 
una alfabetización en sus idiomas nativos: quechua y aymara.

Sus cartillas y método de alfabetización (escritura y lectura), fueron sobre la base de los silabeos y la pronunciación de las consonantes onomatopéyicas. Por ejemplo, el Silabario con la doctrina cristiana EspañolQuichua. El objetivo de esta cartilla era enseñar primero la escritura y lectura de los idiomas propios de los indígenas como el quechua y aymara, para posteriormente otorgar la enseñanza del idioma español. Este modo de enseñanza responde a que el indígena pueda manejar su propio idioma tanto en la escritura y lectura:

...escrito con el auxilio de los nuevos caracteres de las doce letras exclusivamente quechuas y aymaras, cuya ortología está publicada, es ponerte en posesión del manejo de tu propio idioma, para que puedas ya grabar en el papel tus ideas, acumular tus pensamientos, aprovecharte de los ajenos, romper tus tinieblas y divisar siquiera un rayo de las luces del mundo intelectual ... Estudia pues y aprende de memoria la escala onomatopeya y escribiréis y leerás con facilidad tu quechua o tu aymara (Beltrán, 1872, p. I).

Beltrán reconoció que la educación moral sería por medio de la evangelización y la catequización bilingüe. Mediante el idioma materno y español, aprenderían los valores cristianos y morales: honestidad, sinceridad, bondad y solidaridad.
Pero no solamente bastaba una educación indígena, bilingüe y moral, sino también lo productivo. Beltrán (1870), comprendió que los indígenas aparte de tener instrucción elemental: leer y escribir, operaciones aritméticas; tenían que "tener industria." La cual debía estar orientada a brindar los elementos necesarios, como la enseñanza de ciencias y artes, para que puedan subsistir mediante la agricultura, la producción de artesanías y su comercialización, sin que recurran a la mendicidad. Esto evidencia que Beltrán realiza un aporte pionero sobre la vocación productiva de la educación, lo que en la actualidad se viene implementando a través de la Ley 070 de educación "Avelino Siñani y Elizardo Pérez" (2010).

Para Beltrán la educación indígena, bilingüe, moral y productiva constituían los elementos indispensables:

...para elevar al indio al rango de pueblo, a la dignidad del ser inteligente, sociable y ameno. Porque la ignorancia, perpetúa la esclavitud. La inmoralidad, elemento disolvente, destruye al individuo, a la familia y a la sociedad. La mendicidad, fuente de abyecciones, produce los atentados y la prostitución al Poder (Beltrán, 1870, p. 15).

En este sentido, Beltrán es un indigenista que contribuyó a comprender la importancia de la cultura, historia y lengua para generar una educación indígena $\mathrm{y}$ 
bilingüe que tiene como fin la liberación del indígena de su condición colonial.

\section{Palabras finales}

En los últimos 40 años del siglo XIX, la educación pública en Bolivia estuvo sumergida en una marea de iniciativas aisladas implementadas en los distintos gobiernos. Por lo tanto, no hubo una directriz de ampliación de la educación hacia las mayorías indígenas, pese a que la instrucción primaria era obligatoria. Una probable respuesta es la carencia de recursos económicos, las coyunturas políticas internas (disputas por el poder político) y externas (Guerra del Pacifico de 1879), la escases de maestros formados en escuelas normales y el alcance urbano de las jurisdicciones municipales.

La educación indígena no tuvo la atención respectiva del Estado, esta quedó a iniciativa de las municipalidades, de los párrocos y de los propios indígenas. Para los gobernantes y sectores dominantes las políticas agrarias generarían la incorporación de los indígenas a la nación, mediante su conversión en colonos. En ese sentido, la instrucción debía generar su integración a través de su civilización y castellanización en las escuelas.

$\mathrm{Si}$ bien hubo una propuesta pedagógica de Corral (1871) su horizonte de educación indígena buscaba la aculturación a la forma de vida del mundo occidental. La homogeneización de la diversidad a través de su castellanización, su civilización y su ciudadanización, por ende, esta integración en lo biológico buscaba el mestizaje; en lo sociocultural, la selección de valores occidentales y cristianos, y la descalificación social y cultural; y en lo político, una ciudadanía restringida de segunda clase.

Con este contexto histórico en donde se tiene una paradoja de la situación de los indígenas, surge la experiencia educativa del padre Beltrán, el cual desarrolla desde el indigenismo, por ello su proyecto de civilización toma como base la reivindicación del mundo indígena, revalorización de su historia, su cultura, sus idiomas.

De este modo, despliega y desarrolla una educación indígena y bilingüe en la alfabetización y cristianización de quechuas y aymaras. Lo que hace evidente que su proyecto de castellanización no busca suprimir el idioma materno, sino una revalorización de su identidad cultural como base de la educación bilingüe, intercultural y productiva que recurre a materiales y métodos propios, de acuerdo a la realidad cultural y lingüística de los indígenas. Por lo que se aprecia los 
principios de la etnoeducación que Beltrán despliega en su experiencia educativa.

La contribución de Beltrán refleja su aporte pionero de la corriente del indigenismo, el legado de educación propia, bilingüe, intercultural y productiva, es un ejemplo, de la existencia de experiencias, propuestas y proyectos educativos que están presentes en la memoria escrita y oral de la historia de la educación en Bolivia, que están a la espera de nuevas investigaciones que las visibilicen.

El legado de Beltrán en la actualidad recobra vitalidad en la ley 070 de educación “Avelino Siñani y Elizardo Pérez", aunque las propuestas de Beltrán no son las bases de discusión teórica del actual Modelo Educativo Sociocomunitario Productivo, pero sus postulados de educación bilingüe, intercultural y productiva dialogan con la búsqueda de la bolivianidad de la educación y los postulados de la ley 070: descolonización, interculturalidad e intraculturalidad.

En suma, el aporte de Beltrán a la educación indígena en Bolivia y Latinoamérica son las bases del indigenismo y la importancia de la revalorización cultural para la construcción de una educación plural, intercultural y propia, que es desde la etnoeducación.

\section{Referencias}

Alcocer, M. (1872). Breves reflexiones sobre la situación política, moral y administrativa de Bolivia. Cochabamba: Imp. Gutiérrez.

Barnadas, J. (2002). Presbítero Carlos Felipe Beltrán. En Barnadas, J. (Dir.) Diccionario histórico de Bolivia. T. I (pp. 282-283). Sucre: Grupo de Estudios Históricos.

(1998). Carlos Felipe Beltrán: Un párroco boliviano amigo de los indios. Oruro: CEDIPAS.

Beltrán, C. F. (1892). Civilización del indio. Catecismo ó esplicación de la doctrina cristiana del ilustrísimo Claret vertido a la quichua para la instrucción del indio quichuista, por el Cura C. F. B. Oruro: Tipografía de "El Progreso".

_ (1890). Civilización del indio. Doctrina cristiana en castellano y quichua muy mejorada y ampliada en la versión: con licencia del S. S. Ilustrísima el Gobernador Eclesiástico, por el Cura de Toledo C. F. B. Oruro: Tipografía de "El Progreso".

_ (1888). Cotidiano en el idioma qhichua. Oruro.

_ (1872). Civilización del indio. Silabario con la doctrina cristiana EspañolQuichua, ampliada y mejorada de la primera edición con licencia de S. S. Illma. El Gobernador Eclesiástico de la Arquidiócesis "La Plata" por el Cura Carlos Felipe Beltrán. Oruro: Imprenta Bolívar de C. F. Beltrán. 
(1870). Civilización del indio. Ortología de los idiomas quichua y aymara con la invención de nuevos sencillos caracteres. Oruro: Imprenta boliviana de C. F. Beltrán.

Beltrán H., A. (1948, 29 de febrero). Cincuentenario de la muerte de un Apóstol boliviano. La Patria, pp. 51-53.

Bolivia. El Porvenir, (1885, 8 de abril). Instrucción pública, p. 2.

Bolivia. La Violeta (1895, 9 de mayo). Instrucción, p. 2.

Bolivia. Redacción de La Ley, (1887, 19 de marzo). Educar e instruir al pueblo. $L a$ Ley, p. 2.

Choque, R. \& Quisbert, C. (2006). Educación indigenal en Bolivia. Un siglo de ensayos educativos y resistencias patronales. La Paz: Unidad de Investigaciones Históricas Pakaxa, IBIS.

Corral, C. (1871). La Doctrina del Pueblo. La Paz: Imp. Paceña.

Iño, W. G. (2010). La educación del indio en Oruro moderno. En Mendieta, P. (Coord.) Vivir la modernidad en Oruro 1900-1930. (pp. 285-319). La Paz: Instituto de Estudios Bolivianos-UMSA.

_ (2009). Inicios de la formación docente, en la reforma educativa liberal (19001920) En Aillón, E., Calderón, R. \& Talavera, M. L. (Comps.) Miradas retrospectivas a la educación pública en Bolivia. A cien años de la fundación de la Escuela Nacional de Maestros de Sucre (1909). (pp. 117-145). La Paz: Carrera de Historia-UMSA.

Irurozqui, M. (2001). "La guerra de civilización" la participación indígena en la Revolución de 1870 en Bolivia. Revista de Indias, vol. $L X I, N^{\circ} 222$, 407-432.
(1999). La ciudadanía clandestina: democracia y educación indígena en Bolivia, 1826-1952. Estudios Interdisciplinarios de América Latina y el Caribe, vol. 10, $N^{o} 1,61-87$.

Mamani, C. (1991). Taraqu 1866-1935. Masacre, guerra y "renovación" en la biografía de Eduardo L. Nina Qhispi. La Paz: Aruwiyiri, Taller de Historia Oral Andina.

Massud, S. (2006). El Padre Carlos Felipe Beltrán: indigenista y lingüista. En $I V$ Centenario de la Fundación de Oruro. (pp. 27-29). Oruro: La Patria.

Medinaceli, C. (1944, 7 de septiembre). Apuntes sobre el arte de la biografía. La Razón.

Platt, T. (1982). Estado boliviano y ayllu andino. Tierra y tributo en el Norte de Potosí. Lima: Instituto de Estudios Peruanos.

Podesta, J. (1987). ¿Educación popular o etnoeducación? Una propuesta de educación alternativa con grupos étnicos. Iquique: Centro de Investigación de la Realidad del Norte.

Rivet, P., \& Rodríguez, O. (1951). Un apóstol boliviano. Kollasuyo $N^{\circ} 68,79-94$.

Rodríguez, G. (1995). Estado y Municipio en Bolivia. La Ley de Participación Popular en una perspectiva histórica. La Paz: Ministerio de Desarrollo y Medio Ambiente.

Rodríguez, F.; Barrios, I. \& Fuentes, M. T. (1984). Introducción a la metodología de las investigaciones sociales. La Habana: Política.

Suárez, F. (1963). Historia de la educación en Bolivia. La Paz: Trabajo. 
Ticona, E. (2004). La Revolución boliviana de 1952 y los pueblos indígenas. Temas Sociales $N^{\circ} 25,1-14$.

Torrico, B. (1947). La pedagogía en Bolivia. La Paz: Don Bosco.

\footnotetext{
${ }^{\text {i }}$ El artículo es parte del estudio: "Educación y ciudadanía en el siglo XIX: políticas, proyectos y propuestas educativas en Bolivia" realizado en las gestiones 2010-2012, en el proyecto Relaciones Interétnicas del Instituto de Estudios Bolivianos de la Universidad Mayor de San Andrés.

ii Según Rodríguez, Barrios y Fuentes (1984), es el estudio de los acontecimientos, causas, hechos y condiciones históricas en que surgen y se desarrolla un objeto o proceso determinado. En el artículo se describe y analiza la experiencia educativa del padre Beltrán con respecto a la educación indígena en Bolivia.

iii El artículo toma como escenario histórico las últimas décadas del siglo XIX entre 1862-1892.

iv Se ha consultado periódicos de la época, documentos y cartillas de alfabetización, así como bibliografía de historia de la educación boliviana y estudios biográficos del padre Beltrán.
}

Recebido em: 01/03/2017 Aprovado em: 24/03/2017 Publicado em: 31/07/2017
Como citar este artigo / How to cite this article / Como citar este artículo:

APA:

Iño, W. G. D. (2017). El Padre Carlos Felipe Beltrán: planteamientos de una educación indígena y bilingüe en Bolivia (1862-1892). Rev. Bras. Educ. Camp., 2(2), 563-580. DOI: http://dx.doi.org/10.20873/uft.2525$\underline{4863.2017 \mathrm{v} 2 \mathrm{n} 2 \mathrm{p} 563}$

ABNT:

IÑO, W. G. D. El Padre Carlos Felipe Beltrán: planteamientos de una educación indígena y bilingüe en Bolivia (1862-1892). Rev. Bras. Educ. Camp., Tocantinópolis, v. 2, n. 2, p. 563-580, 2017. DOI: http://dx.doi.org/10.20873/uft.25254863.2017v2n2p563

\section{ORCID}

\section{Weimar Giovanni Iño Daza}

http://orcid.org/0000-0002-7691-4816 